\title{
Spiritual Well Being of Heterosexual and Homosexual: A Comparative Study
}

\author{
Rishika Tripathi ${ }^{1}$, Dr.Priyanka Kacker ${ }^{2}$ \\ ${ }^{1}$ Student, Department of Psychology, The M.S.University of Baroda, Gujarat, India \\ ${ }^{2}$ Lecturer, Department of Psychology, The M.S.University of Baroda, Gujarat, India
}

\begin{abstract}
Spirituality has been defined in numerous ways which include; a belief in a power operating in the universe that is greater than oneself, a sense of interconnectedness with all living creatures, and an awareness of the purpose and meaning of life and the development of personal, absolute values. It is the way a person finds meaning, hope, comfort, and inner peace in one's life. Spirituality cannot be explored using scientific methods because it involves deeply personal, subjective experiences, and in this it differs from the over-riding ambition of science: to be objective. Well being is not just the absence of diseases or illness. It is a complex combination of a person's physical, mental, emotional and social health factors. Well being is strongly linked to happiness and life-satisfaction. In short, well being could be described as how one feels about oneself and one's life. The main purpose of the paper is to find out whether Homosexuals (Gays) who are different in their sexual orientation may have different spiritual well - being as compared to hetero sexual. Being a human -spirituality of homosexuals may match with the heterosexual but because of their sexual orientation they may have different well being as compared to heterosexuals. To study this spiritual well-being scale was used. The scale was given to 60 males (30 heterosexuals and 30 homosexuals) of age between 21 to 40 years. The result shows that there is no significant difference in the spiritual well-being, religious well-being and existential well-being of homosexuals (Gays) and heterosexuals male.
\end{abstract}

Keywords: Spiritual Well-Being, Homosexual, Gays, Heterosexual.

\section{Introduction}

Spirituality and sexuality both plays a major role in everybody's life. Regardless of whether young or old, Indian or American, Man or Woman, it is an integral part of what we do who we are. This paper will explore Spiritual Well Being of Heterosexuals and Homosexuals.

Sexual orientation: Human sexual behavior is different from behaviors of other lower animals; it is that it seems to be driven by variety and interplay of different factors. That is, while lower animal or species are driven by a force to reproduce and therefore take part in sexual behavior, humans are not active for the sake of reproduction, rather there are a variety of factors which lead human to enter into a sexual activity. Human sexuality is the ways in which we experience and express ourselves to different people. It plays a major role in our life. Whether we are male or female it is one of the most important factors in development of our individual sexuality. Further, it is an integral part of our personalities and whether we are aware of it or not [1]. Sexual preference is a long lasting pattern of emotional, romantic and sexual attraction to man, woman, or both sexes. Sexual preference means whether the person is attracted towards same sex or opposite sex, associated behaviors and community membership. From several years researchers exhibited that sexual preference exclusive attraction to opposite sex to exclusive attraction to same sex. Therefore, sexual orientation is divided into three categories: heterosexuals (having emotional and sexual attraction towards opposite sex), homosexuals (having emotional and sexual attraction towards same sex) bisexual (having emotional and sexual attraction towards both sexes that is male and female). Different cultures and societies use different kinds of labels like, lesbian (women attracted towards women), gay (men attracted towards men), and bisexual (men and women attracted to both sexes). The components of sex and gender is distinct from sexual orientation like biological sex (anatomical, physiological and genetic characteristics linked with being male or female), gender identity (the sense of being male or female), social gender role (the norms of society that defines masculine and feminine role of a person). This perspective is incomplete if sexual orientation is not referred in terms of relationship with other partner. By portraying their behavior with others people expresses their sexual orientation. Thus sexual orientation is firmly connected to close personal relationship that fulfills deeply felt needs for love, care and respect. Therefore individual personality cannot be judged by the single characteristic of sexual orientation. Rather, it elaborates overall how individual behaves in a society and works keeping in mind their sexuality [2]. 


\subsection{Homosexuality}

Homosexuality is not a psychiatric disorder or a medical problem instead it is a condition linked with certain medical risks. It has long been diagnosed in humans despite the comparative frequency of homosexuality it remains misunderstood and debatable in society. Homosexual's members who choose partners of the same sex for sexual relations and domestic partnership is often discriminated by health care professionals and even become targets of prejudice. For years homosexuality is in question whether it is an environmental construct or biological construct. The phenomena of homosexuality are complex. The studies of homosexuality are hampered by a clear definition that is overlapping heterosexuality and homosexuality [3]. The biological model gives a little understanding regarding homosexuality. Genetics comes under the area of medical science. Science has found that sexual orientation is some of the complex aspects of people [4]. Bailey and Pillard, 1991 conducted a research on twins and reported that when one twin is homosexual the chances of another twin being homosexual is more than general rates of homosexuality. But this does not mean that genetics is only responsible for homosexual behavior. Interestingly this study also looks upon the rest of the family to study homosexuality including adopted brothers and found that rate of homosexuality is $200 \%-300 \%$ more frequent than general rate in society. So it cannot be said that genetic alone is responsible for this because it is even founded in adopted brothers who are not genetically linked [5]. Alfred Kinsey, 1948 from the University of Indiana had done research on human sexuality he had two goals for his test 1) to find out how many adult males are engaged in homosexual behavior 2) to suggest theories about it came to be. When the people were asked if they had engaged in homosexual sexual relation a large percent population had answered no however when they were asked if they had engaged in same-sex sexual relation they answered yes. Orgasm from homosexual activity is felt by $30 \%$ of males. The result of this research had become widely popularized as Kinsey scale of sexuality. The scale covers all individual on a continuum of sexuality ranging from $100 \%$ heterosexual to $100 \%$ homosexual and everyone in between [6]. Researchers conducted an experiment on anatomical and post-mortem structure of gay man's brain. It shows that the portion of the brains hypothalamus of heterosexual and homosexual is different in structure. Hypothalamus is that portion which is related to the sexual drive and function. The results show that homosexual brain's hypothalamus is twice the size of heterosexual brain [7]. To find other possible causes which were not genetic but biological in nature for this researchers studied brain structure, hormones, psychological and sociological causes and the findings shows that there may be biological difference between homosexuals and heterosexuals but it was not sure whether it cause homosexuality or homosexual activity and evidences shows that sexual orientation is not fixed but changeable [4]. Hooker 1957, study was meant to find out the relationship between homosexuality and psychological development and illness. Hooker studied both heterosexual and homosexual and matched groups for age, intelligence quotient (IQ) and educational level. Three psychological tests were given to them they are rorschach inkblot test, thematic Apperception Test and make a picture story test. The result shows no significant difference in any of the three tests. Because answers scores similar for both the groups, researcher concluded a zero correlation between social determinism of sexuality. As a result of finding American psychological association had removed homosexuality from diagnostic and statistical manual of psychological disorder. After 1975 American psychological association had declared that homosexuality is a way people express their love towards others [8]. When all the work has been put together to find out causes for sexual orientation it is first, science cannot provide a firm answer. Second most researchers agree that the causes of same -sex attraction are complex and many factors contribute to the development of same sex attraction like biological, sociological and psychological [4].

\subsection{Heterosexuality}

Heterosexuality is old as procreation, and as ancient as the lust of Adam and eve. People suppose that it is the most normal, essential, unchanging desire. The use of the word heterosexual first appeared in medical journal article by Dr. James G. Kiernan of Chicago in 1892. But for Kiernan heterosexuals were not normal, he defined them suffering from a medical condition named physical hermaphroditism by this he means inclination towards both sexes. In the same year in 1892 Dr. Krafft-Ebing's influential psychopathia sexualist published in United States. However, Kiernan's and Ebing's thought were different from each other. In Ebings book, 1892 the term heterosexual means erotic feelings towards different sex and in his book heterosexuals and homosexuals are completely different from third sex that is hermaphroditism erotic feeling towards both sexes. Gradually, doctors agreed that heterosexuals are normal in nature. In 1901, Dorland medical dictionary, published in Philadelphia continued to define heterosexuality as abnormal or perverted appetite toward the opposite sex hunger. But that craving was still aberrant. The twentieth century witnessed the decreasing legitimacy of that procreative imperative, and the increasing public acceptance of a new hetero pleasure principle. Gradually, heterosexuality came to refer to a normal other sex sensuality free of any essential tie to procreation but only in the mid 1960s hetero eroticism be distinguished completely free from reproduction and male female pleasure sex justified for itself [6]. 


\subsection{Spirituality and Well-Being}

Spirituality go deep inside human existence, it is our relation to god. In our daily life spirituality is always present in the background and move with us each and every time. It is like an inspiration and an orientation. Sometimes, however spirituality itself forces inside our consciousness and it demands shaping and thorough reflection [7]. Spirituality helps us to seek who we are what we are and where we want to go and it enters in the depth of our lives where we discover ourselves and our internal connectedness with the eternal power. Spirituality enables us to see light in the darkness, discover meanings, see beauty, experience love, and know that we are made for love. Spirituality is the medium which connects us to god and tell us our right and wrong deeds. Spirituality empowers us to think and reflect light on the darkness, discover significance, find beauty, experience love and should know that we are made for love.

Holistic perspective: spirituality is the preliminary step to understand who we are. Holistic paradigms values humans for their wholeness, integrated body-mind spirit and ongoing interaction with the environment. It is the illusion of mind that body, mind and spirit are separate parts of person's body. Rather it is intertwined and interpenetrating unity. Within the holistic perspective spirituality cannot be kept apart from our lives and experiences we face at each and every point of time. As we embrace all spheres of our life we are moving forward to know are spirituality better. But everyone has a different perception to view spirituality. If viewed from only one perspective than it is difficult to understand it completely.

Relationship between spirituality and religion: spirituality is often talked in terms of religious beliefs and practices. Some people believe that if someone is not attending religious practices or do not believe in god is not spiritual. We can see this in hospitals settings when doctors and nurses link patient religious affiliation with his or her spirituality. However spiritual care giving is more effective when we understand the concept that it is a broader term than religion. May be the person is spiritual but not religious [8].

Well-Being: The fulfillment of goals which is derived from the idea of positive well-being. Which lie along a hierarchy from basic needs to desires, it is a key concept of engaging in activity may be intrinsically rewarding and leads to goal fulfillment in them. A sense of well-being is reflected I what has been achieved in doing an activity, this is based on the eudaimonic perspective of well-being. It is an Aristotelian viewpoint-that living a life of virtue is of greater worth than seeking out pleasure. The focus is on the meaning in life, self realization and the extent to which a person is functioning fully. The alternative approach is hedonic view based on the philosophy of Aristippus is that fundamental goal in life and achievement of happiness is maximizing of pleasure. An important element in achieving positive well-being is ability to manage one's life in relation to one's surrounding environment and by immunizing against bad fortune and by having the ability to understand events and taking in control of the damage they do. A modern concept of well-being are beginning to address the complexities of recognition of individual lifestyle choices set within the context of personal, political and social control [9]. Following are the researches on spirituality of homosexuals:

Research on finding a way with religion and spirituality: the intersection of religion, aging, and sexual orientation from the respective of lesbian older adults. This was a qualitative study researcher used semistructured interviews of 20 lesbians older adults who are engaged with religion and spirituality across their life spans. Participants were purposefully selected and snowball sampling was used. The results show that the participants in this study reported little religious conflict related to sexual orientation. The vexed relationship with religion did not seem to hinder the ability of participants to meet the religious need as they aged. [10].

Research on the spiritual life of gays and lesbian individual is based upon telephone interviews conducted by a group in 9 nationwide random samples of adults. In the course of the 9232 interviews were conducted, each respondent were asked whether they are gay, lesbian, heterosexuals and bisexuals. The results shows that the gay people are interested in faith but not in the local church and do not appear to be focused on traditional tools and tradition that represent comfort zone of most churched Christian. And there were clear substantial difference between the spiritual practices of straight and gay individuals. [11].

Research on importance of spirituality among gays and lesbians individual .According to the researcher religion is the most important factor in expressing spirituality. Religion condemns any form of homosexuality people expect that gays and lesbians have little to do with spirituality. The study investigated the spirituality of 93 gays and lesbians individuals. The result revealed that respondents espoused high level of spiritual wellbeing: how one relates to god (religious well-being), and how one feels about life (existential well-being). Those who identified themselves with a formal religion and who attended religious services frequently has higher religious well-being. Multiple regression analyses revealed that existential well-being was a significant predictor of adjustment: having high self-esteem, accepting one's homosexual orientation and feeling less alienated. In contrast religious well-being was not a significant predictor of any measure of adjustment. [12]. 


\section{Methodology}

The objective of the study is to find out spiritual well-being of heterosexuals and homosexuals a comparative study. This research is carried out to ventilate the reasons behind different sexual orientations. Being homosexual or heterosexual how they differ in their spirituality and their level of wellness.

\subsection{Variables:}

Independent Variable: Level of spiritual well-being.

Dependent Variable: Type of sexuality.

\subsection{Hypothesis:}

1. There will be significant difference in overall spiritual well-being of heterosexuals and homosexuals.

2. There will be significant difference in religious well-being of heterosexuals and homosexuals.

3. There will be significant difference in existential well-being of heterosexuals and homosexuals.

\subsection{Sample:}

The method used for selecting the homosexual's gay participants is purposive sampling, a kind of non probability sampling one which is based on typicality of the cases to be included in the sample the researcher has some belief that the sample being involved is typical of the population or is a very good representative of the population and the method used for selecting heterosexual's male participants is random sampling, a kind of sampling in which each and every individual has equal chances of getting selected for the study. Total of 60 participants were selected for the research (30 homosexual gays and 30 heterosexual males) between the age ranges from 18 years - 40 years from the city Vadodara, Gujarat. The homosexuals were selected from the organization named Lakshya trust who primarily works on various issues addressing and advocating the social, economic, legal, psychological, and spiritual and health aspects of sexual minorities (gay, bisexuals and transgender population). Following are the inclusion and exclusion criteria for sampling.

Inclusion criteria- people who are between the age of 18years to 40years, 30 gays and 30 males were selected for the study.

Exclusion criteria- participants who are below 18years and above 40years, female, lesbians and bisexuals were not selected for the study.

\subsection{Diagnostic tool:}

For the research purpose Spiritual Well-Being Scale (SWBS) developed by Paloutzian and Ellison was used. The SWBS is a 20 item paper-pencil instrument. 10-15 minutes are required to fill the questionnaire. Each item is answered on a 6-point likert scale (strongly degree, moderately agree, agree, disagree, moderately disagree, strongly disagree). Ten of the statements assess religious well-being and contain the word god and other ten of the statements assess existential well-being and have no religious connotation. These statements are about life-satisfaction and direction. Approximately half of the questions are negatively phrased in order to control any response bias. The reliability for spiritual well-being ranges from .89 to .94 , religious well-being .82 to .94 , existential well-being .78 to .86 . The spiritual well-being scale has good face validity as is evident by the content of the items. There are three primary scoring for this test spiritual well-being, religious well-being and existential well-being.

Spiritual well-being scoring: Each SWBS positively worded items is scored from 1-6, with a higher number representing greater well-being; negatively worded items are reversed scored. Positively worded item are numbered $3,4,7,8,10,11,14,15,17,19$ and 20 . For these items strongly agree is given a score of 6 , moderately agree scored 5 , agree scored 4 , disagree scored 3 , moderately disagree scored 2 and strongly disagree scored 1. Negatively worded items are numbered 1,2, 5, 6, 9, 12, 13, 16 and 18. For these items strongly agree is given a score of 1 , moderately agree scored 2 , agree scored 3 , disagree scored 4 , moderately disagree scored 5 , strongly disagree scored 6.

Religious well-being scoring: Each SWBS odd numbered items 1, 3, 5, 7, 9, 11, 13, 15, 17 and 19. Is scored from 1-6 starting from strongly agree to strongly disagree.

Existential well-being scoring: Each SWBS even numbered items 2, 4, 6, 8, 10, 12, 14, 16, 18, and 20. Is scored from strongly agree to strongly disagree.

\subsection{Procedure:}

The purpose of the research was to study spiritual well-being of homosexuals and heterosexuals. In which there were two dimensions religious well-being and existential well-being. For this purpose, two groups were formed, in group 1 there were 30 heterosexual males and in group 2 there were 30 homosexual (Gays) within the age 18-40 years. The method use for selecting homosexual's gay participants is purposive sampling, a kind of non-probability sampling, one which is based on typicality of the cases to be included in the sample the 
researcher has some belief that the sample being involved is typical of the population or is a very good representative of the population and the method used for selecting heterosexual's male participants is random sampling, a kind of sampling in which each and every individual has equal chances of getting selected for the study. The spiritual well-being scale consisted of 20 questions and participants has to encircle the option which suits best to them based on 6 point likert scale (strongly agree, moderately agree, agree, disagree, moderately disagree, strongly disagree). Participants were instructed to complete the questionnaire as fast as possible, do not leave any question unmarked, they were asked not to think a lot for a particular question. The questionnaire was given to the participants and they were asked to read each and every question carefully and if any doubt comes in any question clarify it immediately. After that mean and "t-test" was used to examine overall spiritual wellbeing, religious well-being and existential well-being with the help of statistical package for social sciences (SPSS).

\subsection{Discussion:}

The objective of the study is to find out the Spiritual Well-Being of Gays and heterosexual Males: a comparative study. For this purpose, 60 participants were selected 30 homosexual (Gays) and 30 heterosexual (Males) within the age of 18-40 years. The method used for selecting homosexual gay and heterosexual male participants was purposive and random sampling method. The participants were provided with the questionnaire and they were instructed to fill the questionnaire as soon as possible, do not leave any question unmarked and if any doubt comes clarify it immediately. After that data was tabulated, mean and "t"-test was done to see the significant difference in the overall spiritual well-being, religious well-being and existential well-being of the participants with the help of statistical package for social sciences (SPSS).

Table 1: Showing means scores of heterosexual (males) and homosexual (gays)

\begin{tabular}{|c|c|c|}
\hline & Heterosexual (Males) & Homosexual (Gays) \\
\hline Religious well-being & 29.53 & 29.77 \\
\hline Existential well-being & 31.33 & 29.00 \\
\hline Overall spiritual well-being & 90.37 & 97.17 \\
\hline
\end{tabular}

TABLE-1 shows the mean scores of religious well-being, existential well-being and overall spiritual wellbeing. There is a slight difference of scores between the said. The difference in sexual orientation is a natural phenomenon and does not carry any abnormality along with it. So, heterosexuals and homosexuals share similar level of religious and existential well-being. When we look at the mean scores of overall spiritual well-being of heterosexuals and homosexuals difference is there. May be it is because of the deprivation they face in society so they find satisfaction near to god and feel that god is the only medium whom they can rely upon and share their feelings to.

Table 2: Showing the significant difference between the mean scores of heterosexual (males) and homosexual (gays).

\begin{tabular}{|c|c|c|}
\hline & Heterosexual (Males) & Homosexual (Gays) \\
\hline & Sig " $\mathrm{t}$ " & Sig " $\mathrm{t}$ " \\
\hline Religious well-being & .890 & .890 \\
\hline Existential well-being & .201 & .201 \\
\hline Overall spiritual well-being & .78 & .78 \\
\hline
\end{tabular}

There is no significant difference in the religious well-being, existential well-being and overall spiritual wellbeing of heterosexuals (males) and homosexuals (gays). It is because the only difference in them is their sexual orientation and it is not an abnormality because of which they should differ in their spirituality and wellness. The life of homosexual and heterosexual are similar just that orientation of homosexual towards their sexual partner is different, but that does not mean that their spiritual well-being will be different from heterosexuals. They equally believe in god and know in which direction their life is going in. Though they face lots of problems in leading their life because of society's stereotypical thinking pattern, they find it hard to move in society with others not because they know they are odd in comparison to others because of other people who think they are different from them. Homosexual (gays) carry the same level of religious well-being because they feel god is always there with them in their hard times and help them whenever they are in need. They equally attend religious services and offerings. Even they have a good existential well-being because most of them know who they are, what they want from life and where there life is heading in. They are quite satisfied with the life they have and want it to be better with time but at least they are not upset with this fact that they are homosexuals. In 1973, American psychological association removed homosexuality from Diagnostic and Statistical Measure of Mental Disorders (DSM) because they even found that homosexuality is normal in nature 
it's just that their sexual orientation is different from others but this is not creating any sort of problems in their life. Abnormality is considered when something is becoming an obstacle in your work and present day life because of which people are facing hindrances in doing their work. But in the case of homosexuals their sexuality is not becoming hindrance in their work and other settings. They are leading their life as normal as others it's just that society is not letting them live their life normally. Same way, this study also found that they have same level of spirituality and wellness as heterosexuals. Lastly, would like to add that while conducting the research, it has been found that the homosexuals are deprived of the respect, love and care as compared to other sections of society because of their orientation.

\section{Conclusion:}

As the researches show that homosexuality are neither a biological construct nor an environmental construct and no theory or experiment lead to a definitive answer. Some people give importance to Swaab's theory while other give importance to Hooker's finding. Perhaps there is no single answer for sexual orientation; all are a cause of complex interaction between biological, environmental, cognitive and anatomical factors shaping an individual at an early age. This research mainly focuses on spiritual well-being of heterosexual males and homosexual gays and the results shows that there is no significant difference in spiritual well-being of heterosexuals and homosexuals. They just have the different orientation and because of that they have a different physical appearance but it does not give rise to altogether different thinking and perceptual style. The advantage of this research is that it tells us that both homosexual and heterosexual are normal in nature and it even checks the fact that American psychological association removed homosexuality from DSM II because they considered it normal in nature and this research also gets same results. The limitation of the study is that it was conducted on a small population due to availability of data and because of that generalization is difficult. Further this research can be extended on a larger population, even urban and rural homosexual population can be segregated and can be compared, and different cultures homosexual and heterosexual population can be collected for study and interventions can be planned for homosexuals.

\section{References:}

[1] A.R. Rathus, J.S. Nevid and L. Fichner-Rathus, human sexuality: in a world of diversity (Boston, Allyn and Bacon, 1993).

[2] American Psychological Association, Answers to your questions for a better understanding of sexual orientation and homosexuality, American Psychological Association, 2008.

[3] P.H. Bazemore, Homosexuality, Medscape, 20011.

[4] D. Hamer \& P. Copeland, the science of desire: the search for the gay gene and biology of behavior (New York, Simon \& Schuster, 1994).

[5] J.M.Bailey, \& R.C. Pillard, A genetic study of male sexual orientation, Archives of General Psychiatry, 48, 1991, 1089-1096.

[6] A. C. Kinsey, A. B. Pomeroy \& C. E. Martin, sexual behavior in the human male (Philadelphia: W.B, Saunders, 1948).

[7] R. D. Johnson, Homosexuality: nature or nurture, AllPsych Journal, 2003.

[8] E. Hooker, The adjustment of the male overt homosexual, Journal of Projective Techniques, 21, 1957, 18-31.

[9] J. N. Katz, the invention of heterosexuality (United States of America, The University of Chicago Press Ltd London, 2007). 83-88

[10] K. Waaijmaan, spirituality: forms, foundation, methods (Bondgenotenlaan Leuven, Peters, 2002 ). 1.

[11] M. A. Burkhardt, and M. G. N. Jacobson, spirituality: living our connectedness (United States of America, Delmar Thompson Learning, 2002). 3-13

[12] S. A. Beverley, well-being: in search of your good life (Great Britain, The Policy Press, 2008). 1-13.

[13] S.Wanda, finding a way with religion and spirituality: the intersection of religion, aging and sexual orientation from the perspective of lesbians older adults, doctoral diss, university of California, los Angeles, 2008.

[14] G.Barna, spiritual profile of homosexuals adults provide surprising insight, Ventura, California, 2009.

[15] Tan, p. Philip, the importance of spirituality among gay and lesbian individual, doctoral diss, California state university, Long Beach, 2005. 